\title{
FORMULATION AND EVALUATION OF FIXED-DOSE COMBINATION OF BILAYER TABLETS OF ATAZANAVIR SULFATE AND RITONAVIR 300 MG/100 MG
}

\author{
JONNA SANKARAIAH ${ }^{*}$, NEERAJ SHARMA ${ }^{2}$, MOHD JAVED NAIM ${ }^{3}{ }^{*}$
}

${ }^{*}$ Department of Pharmaceutics, Bhagwant University, Ajmer, Rajasthan, India, ${ }^{2}$ Faculty of Pharmacy, Bhagwant University, Ajmer, Rajasthan, India, ${ }^{3}$ Faculty of Pharmacy, Bhagwant University, Ajmer, Rajasthan, India

Email: javednaim88@rediffmail.com

Received: 21 Apr 2021, Revised and Accepted: 13 Jul 2021

\begin{abstract}
Objective: The objective of this study is to formulation and development of fixed-dose combination as a single dosage regimen by using the design of experiments (DOE) approach against the single dose of reference listed drugs of brand reyataz capsule $300 \mathrm{mg}$ (atazanavir sulfate) and norvir tablets $100 \mathrm{mg}$ (ritonavir tablets) to treat human immunodeficiency virus (HIV) Infections.

Methods: Formulation was developed with each blend of ritonavir by using hot-melt extrusion and atazanavir sulfate by wet granulation process and compressed by bilayer technology followed by film coating. Formulation and process optimization by design of experiments (DOE) to evaluate dissolution and related substances of the finished product. Fractional factorial $\left(2^{2}+3\right)$ and full factorial design $\left(3^{3}+3\right)$ by using a design expert (version 11.0) were used to evaluate the formulation and process variables to prepare a robust formulation.

Results: Results indicate that the sorbitan monolaurate range has played a key role to achieve the dissolution for ritonavir formulation. The studied temperature range and interaction of temperature and feed rate, temperature and screw speed during the hot-melt extrusion process impact on the related substances of the bi-layer tablet. Analysis of variance (ANOVA) also finding the P-value less than 0.0500 and the studied range was significant. Design space was established for the significant factors to control the results within the acceptable limits. The studied formulation and wet granulation process for atazanavir sulfate have no significant impact on dissolution and related substances of the finished product. Further, the studied hardness range of 16-28kp for bi-layer tablets has no critical impact on the dissolution. Optimum formulation and process of bi-layer tablets in F37 yielded similar drug release and related substances against the reference drug product.
\end{abstract}

Conclusion: The present invention of fixed-dose combination can be recommended as a single dosage regimen with the consistent drug release and control of the unknown impurities in the prototype formulation against the individual reference drug product.

Keywords: Fixed-dose combination formulation, Human immunodeficiency virus (HIV) infections, Bilayer technology, Quality by design (QbD), Design of experiments (DOE), $2^{3}+3$ and $2^{2}+3$ full factorial and fractional factorial design

(C) 2021 The Authors. Published by Innovare Academic Sciences Pvt Ltd. This is an open-access article under the CC BY license (https://creativecommons.org/licenses/by/4.0/) DOI: https://dx.doi.org/10.22159/ijap.2021v13i5.41860. Journal homepage: https://innovareacademics.in/journals/index.php/ijap

\section{INTRODUCTION}

Fixed-dose combination drugs can be defined as two or more drugs in a single formulation, each drug having independent modes of action, or the combination of which are synergistic or additive, or complementary in their effect. "Free" combinations can be defined as two or more drugs in separate formulations, each taken usually at the same time.

Fixed-dose combination (FDC) products are common in the treatment of hypertension, diabetes, human immunodeficiency virus, and tuberculosis. They make it possible to combine two or more drug molecules with different modes of pharmacological actions in a single dosing unit and optimize the treatment. From a patient perspective, they offer convenience, reduced dosing unit burden, and cost savings. From a clinical perspective, an aging population in developed countries will need multiple medications to treat agerelated diseases and co-morbidities. Fixed-dose combination (FDC) products simplify dosing regimens and enhance patient compliance. The number of fixed-dose combination (FDC) products has grown over the years and the trend is likely to continue. While some formulation technologies such as multi-layer tablets, multiparticulate systems, active film coating, and hot-melt granulation. Historically, fixed-dose combination (FDC) products were developed for improved compliance, better efficacy, and reduced adverse events $[1,2]$. In the current scenario, the strategies for developing a fixed-dose combination (FDC) are primarily based on the therapeutic requirements.

Assessments of the desired benefits such as patient adherence, enhanced efficacy, and better safety profiles compared to the existent drug therapies and possible limitations (e. g., cumulative toxicity) of the combination product are performed. Fixed-dose combination (FDC) product development is governed by regulatory recommendations, where clinical, biopharmaceutical and pharmacokinetic (PK) considerations are critical for their development. One of the main biopharmaceutical considerations is the dose of each active substance in the fixed-dose combination (FDC), which should be appropriately evaluated and clinically justified.

Fixed-dose combinations (FDC) are generally developed with components having complementary mechanisms of action with a clear medical rationale. Typically this is the case for an uncontrolled disease or comorbid condition requiring multi-drug therapy resulting in pill burden. Following are the general clinical considerations for the development of fixed-dose combination (FDC) products [3].

A fixed-dose combination of drugs is considered to be essentially similar or bioequivalent to an innovator drug product. Due to the high costs of the innovator drug products, these are not affordable to the common people. So, the development of generic drugs is very important to afford to common people as well as to reduce treatment costs.

Generic companies are not needed to conduct non-clinical studies and phase I, phase II, and phase III clinical studies to explicit safety and efficacy of the drug products. Instead, generic companies need to show that their generic product is bioequivalent to that of the innovator drug product through bioequivalence studies, thereby making medicines more affordable and more accessible to wider populations preventing drug shortages. Development of fixed-dose formulations becomes very difficult, as the innovator companies used to protect the drug release dosage forms technology, composition, polymers, dissolution profile and biodata through 
patents. The main challenge is developed fixed-dose formulation should pass bio-equivalency studies in fasting and fed conditions and also, the product should be stable and should meet international conference on harmonization (ICH) guidelines. The bio-availability and bio-equivalency will depend on the type of surfactants, solubilizer, diluents, type of polymer used, percentage of disintegrant, and technology used for manufacturing [4].

The quality by design (QbD) approach with the design of experiments (DOE) by statistical evaluation for the formulation and process variables is must prove the consistent results of the finished product. The objective of the design of experiments (DOE) by using full factorial and fractional factorial design is to evaluate the critical material and critical process attributes to affect the responses of the finished product and finally establish the design space for controlling the drug release and unknown impurities of prototype formulations. The current study was used the bilayer tablet concept for the compression of two layers such as ritonavir (Layer-I) and atazanavir sulfate (Layer-II) as a fixed-dose formulation. In addition, compatibility results also recommended to use of bilayer compression to control the related substances within the international conference on harmonization (ICH) guidelines [5-7].

\section{MATERIALS AND METHODS}

\section{Pre formulation studies}

The excipients used in atazanavir sulfate and ritonavir tablets were selected based on the excipients used in the reference drug products. A summary of the excipients-drug substance compatibility was assessed through high-performance liquid chromatography (HPLC) analysis of binary mixtures of excipients and drug substances at a 1:1 ratio in the solid state. Samples were stored at $25^{\circ} \mathrm{C} / 60 \% \mathrm{RH}$ in closed conditions and $40{ }^{\circ} \mathrm{C} / 75 \% \mathrm{RH}$ in both open and closed containers for one 1 month [8].

Based on the evaluation of drug and excipients compatibility study, there is the interaction between drug substances of ritonavir and atazanavir resulted in increases the unknown impurity and it was not compatible. Hence, bilayer compression was recommended. Initial development for atazanavir formulation, direct compression was recommended and it was yielded the variation of assay and content uniformity issues and poor flow of the final blend was observed. Further, the wet granulation method was proposed to improve the content uniformity by controlling the flowability of the granules [9-11]. In the case of ritonavir formulation design, hot-melt extrusion is recommended based on the availability of literature data, previous experience and patents data [12-14].

\section{Tooling details}

Based on the weight and size of individual reference drug product such as reyataz capsule $300 \mathrm{mg}$ (atazanavir sulfate) and norvir tablets $100 \mathrm{mg}$ (ritonavir tablets), bilayer tablets of the test formulation was targeted to $1560.00 \mathrm{mg}$ at compression stage by using punch tooling of $21.20 \times 11.5 \mathrm{~mm}$ during the formulation and process development study.

Initial development of a fixed-dose combination of atazanavir sulfate and ritonavir bilayer tablets $300 \mathrm{mg} / 100 \mathrm{mg}$ was planned with bilayer compression strategy considering ritonavir blend is Layer-I and atazanavir sulfate blend in Layer-II.

The rationale for selecting the manufacturing for atazanavir sulfate based on the fine particle size and poor flowability of active pharmaceutical ingredient (API), wet granulation process was confirmed. In the case of ritonavir, because of the solubility enhancement and patent research data, hot-melt extrusion was selected.

The initial proposal was to use similar qualitative composition as individual reference standards, but the final composition and manufacturing method was selected based on the physicochemical characteristics of the development product [15-17].

Based on the literature search and previous experience, the proposed manufacturing procedure for the formulation was designed as per fig. 1.

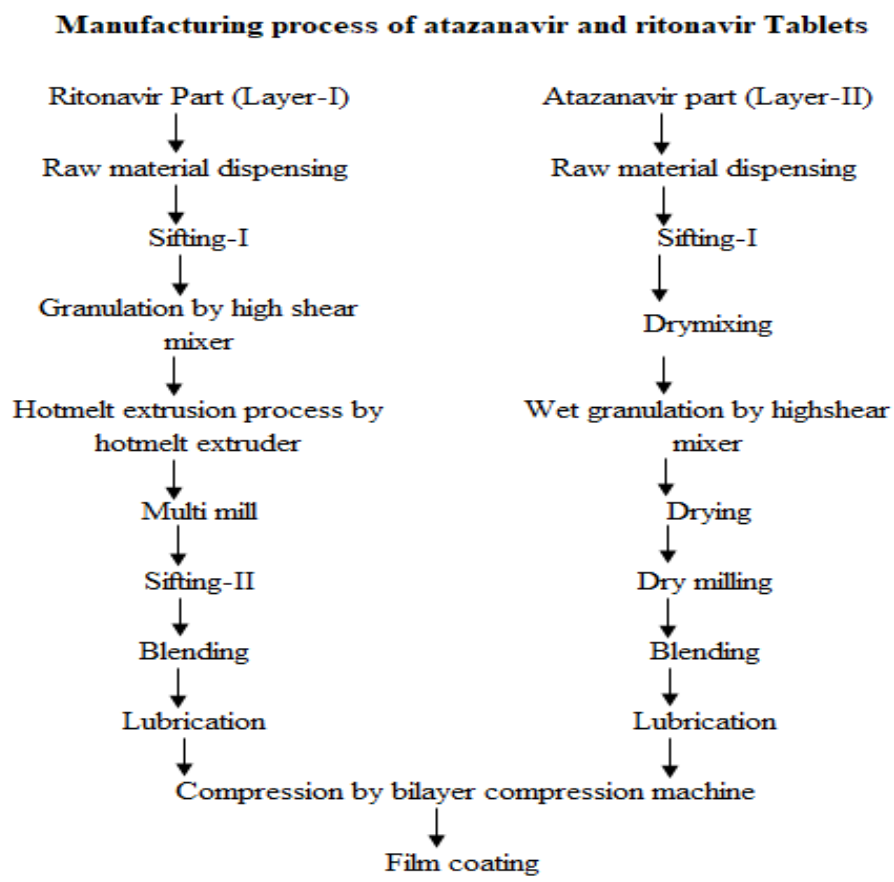

Fig. 1: Manufacturing process of fixed-dose combination (FDC) product

\section{Dissolution method development}

Based on the solubility of drug substances, it showed pH-dependent solubility across the physiological $\mathrm{pH}$ range. But maximum saturation solubility in acidic pH. So, dissolution media of $0.025 \mathrm{NHCL}+0.06$
MPOE10LE/900 ml/100 RPM was selected [18, 19]. Overall dissolution comparison within the formulation was carried out from the batches of $\mathrm{F} 1$ to F37. Hence, a hardness range from $16-26 \mathrm{~N}$ was maintained. Further, test VS reference product dissolution was compared to understand the differences in drug release between the formulations. 


\section{Experimental design}

\section{Formulation of ritonavir part (Layer-I)}

Based on the available patents and reference product composition, ritonavir formulation was manufactured by using wet granulation of dry mix mixture followed by hot-melt extrusion process.

As per the composition table 3, the level of intragranular materials such as sorbitan monolaurate and colloidal silicon dioxide may affect the dissolution. Therefore, the level of intra granular will be determined through formulation optimization (design of experiments) DOE. Formulation of center point batches such as F12, F17, and F18 was observed to be the final composition. This final formulation was compared with other designs of experiment (DOE) batches as per table 3 .

Sorbitan monolaurate was used as a solubilizer and the levels investigated ranged from $40.00 \mathrm{mg}$ to $80.00 \mathrm{mg}$. colloidal silicon dioxide is being used as anti-adherent in the formulation. It may promote the wicking action and ultimately affect dissolution; the levels investigated range from $0.00 \mathrm{mg}$ to $16.00 \mathrm{mg}$.

These levels are considered based on the prior knowledge and inactive ingredient level (IID level) as per Food and drug administration (FDA) and are within the recommended range in the handbook of pharmaceutical Excipients [20].

During the evaluation of formulation design of experiments (DOE) design for the intragranular part of the ritonavir layer. The atazanavir layer of center point composition will be kept constant. Fractional factorial design with 2 factor, 2 level $2^{2}+3$ was selected for the formulation of ritonavir and atazanavir sulfate to evaluate the design of experiments by using a design expert software program $[21,22]$.

Table 1: Design of experiments (DOE) design for ritonavir target formulation (Layer-I)

\begin{tabular}{lll}
\hline Independent variables & Different levels & \\
\cline { 2 - 3 } & Low & Target \\
\hline Sorbitan monolaurate (mg) & 40.00 & 60.00 \\
Colloidal silicon dioxide (mg) & 0.00 & 8.00 \\
Response & Goal & Acceptable Range \\
Diss. in 0.025 N HCL+0.06 MP0E10LE & Maximize & NLT85 (Q)at 120 min. \\
\hline
\end{tabular}

\section{Formulation of atazanavir part (Layer-II)}

In the case of layer-II, study the effect of two formulation factors such as starch 1500 and crospovidone on dissolution was identified as high risk for layer-II. During the evaluation of formulation design of experiments (DOE) design for the intragranular part of the atazanavir layer. The ritonavir layer of center point composition will be kept constant.

Formulation of center point batches such as F23-F25 was observed to be the final composition. This final formulation was compared with other designs of experiment (DOE) batches as per table 4 .

Table 2: Design of experiments (DOE) design for atazanavir target formulation (Layer-I)

\begin{tabular}{lll}
\hline Independent variables & Different levels & Target \\
\cline { 2 - 3 } & Low & High \\
\hline Starch $1500(\mathrm{mg})$ & 10.00 & 25.00 \\
Crospovidone $(\mathrm{mg})$ & 10.00 & 15.00 \\
Response & Goal & Acceptable Range \\
Diss. in 0.025 N HCL+0.06 MPOE10LE & Maximize & NLT85 (Q)at 120 min. \\
\hline
\end{tabular}

Starch 1500 was used as a diluent and the levels investigated ranged from $5.00 \mathrm{mg}$ to $15.00 \mathrm{mg}$. Crospovidone was used as a disintegrant in the formulation. These two factors may affect dissolution; the levels investigated range from $5.00 \mathrm{mg}$ to $15.00 \mathrm{mg}$.

While study for layer-I formulation optimization study as per table 3 , the final blend with the layer-II formulation of the center point batch (F23-F25) was used for the bilayer compression, compression was carried out by using both layers with a bi-layer compression machine (10 stations, Parle Elizabeth) for an average weight of $1560.00 \mathrm{mg}$. Further, all the design of experiments (DOE) batches was evaluated with a hardness range of $16-28 \mathrm{kP}$.

Table 3: Design of experiments (DOE) for ritonavir formulation (Fractional factorial design by a design expert, $\left(2^{2}+3\right)$ )

\begin{tabular}{|c|c|c|c|c|c|c|c|c|}
\hline \multirow[t]{2}{*}{ S. No. } & \multirow[t]{2}{*}{ Ingredients } & F12 & F13 & F14 & F15 & F16 & F17 & F18 \\
\hline & & \multicolumn{7}{|c|}{ mg/tablet } \\
\hline \multicolumn{9}{|c|}{ Intra granular materials } \\
\hline 1 & Ritonavir & 100.00 & 100.00 & 100.00 & 100.00 & 100.00 & 100.00 & 100.00 \\
\hline 2 & Co povidone & 585.00 & 573.00 & 557.00 & 597.00 & 613.00 & 585.00 & 585.00 \\
\hline 3 & Sorbitan monolaurate & 60.00 & 80.00 & 80.00 & 40.00 & 40.00 & 60.00 & 60.00 \\
\hline 4 & Colloidal silicon dioxide & 8.00 & 0.00 & 16.00 & 16.00 & 0.00 & 8.00 & 8.00 \\
\hline \multicolumn{9}{|c|}{ Extra granular materials } \\
\hline 5 & $\begin{array}{l}\text { Dicalcium phosphate } \\
\text { anhydrous }\end{array}$ & 110.00 & 110.00 & 110.00 & 110.00 & 110.00 & 110.00 & 110.00 \\
\hline 6 & Colloidal silicon dioxide & 20.00 & 20.00 & 20.00 & 20.00 & 20.00 & 20.00 & 20.00 \\
\hline 7 & Sodium stearyl fumarate & 7.00 & 7.00 & 7.00 & 7.00 & 7.00 & 7.00 & 7.00 \\
\hline Total & & 890.00 & 890.00 & 890.00 & 890.00 & 890.00 & 890.00 & 890.00 \\
\hline
\end{tabular}

Note: F012, F017, and F18 is target formulation of center point batches

While study for layer-II formulation optimization study as per table 4, the final blend with the layer-I formulation of the center point batch (F12, F17-F18) was used for the bilayer compression. Both blends of layer-I and II were used for the bilayer compression machine (10 stations, Parle Elizabeth) for an average weight of $1560.00 \mathrm{mg}$. Further, all the design of experiments (DOE) batches were evaluated with a hardness range of $16-28 \mathrm{kP}$. 
Table 4: Design of experiments (DOE) of atazanavir formulation (Fractional factorial design by a design expert, $\left(2^{2}+3\right)$ )

\begin{tabular}{|c|c|c|c|c|c|c|c|c|}
\hline \multirow[t]{2}{*}{ S. No. } & \multirow[t]{2}{*}{ Ingredients } & F19 & F20 & F21 & F22 & F23 & F24 & F25 \\
\hline & & \multicolumn{7}{|c|}{ mg/tablet } \\
\hline \multicolumn{9}{|c|}{ Intra granular materials } \\
\hline 1 & Atazanavir sulfate & 341.70 & 341.70 & 341.70 & 341.70 & 341.70 & 341.70 & 341.70 \\
\hline 2 & Lactose monohydrate & 162.00 & 147.00 & 147.00 & 132.00 & 152.00 & 152.00 & 152.00 \\
\hline 3 & Starch 1500 & 10.00 & 25.00 & 10.00 & 25.00 & 15.00 & 15.00 & 15.00 \\
\hline 4 & Crospovidone & 10.00 & 10.00 & 25.00 & 25.00 & 15.00 & 15.00 & 15.00 \\
\hline \multicolumn{9}{|c|}{ Extra granular materials } \\
\hline 5 & Starch 1500 & 50.00 & 50.00 & 50.00 & 50.00 & 50.00 & 50.00 & 50.00 \\
\hline 6 & Crospovidone & 50.00 & 50.00 & 50.00 & 50.00 & 50.00 & 50.00 & 50.00 \\
\hline 7 & Calcium silicate & 40.00 & 40.00 & 40.00 & 40.00 & 40.00 & 40.00 & 40.00 \\
\hline 8 & Ferric oxide yellow & 0.50 & 0.50 & 0.50 & 0.50 & 0.50 & 0.50 & 0.50 \\
\hline 9 & Magnesium stearate & 5.80 & 5.80 & 5.80 & 5.80 & 5.80 & 5.80 & 5.80 \\
\hline Total & & 670.00 & 670.00 & 670.00 & 670.00 & 670.00 & 670.00 & 670.00 \\
\hline
\end{tabular}

Note: F023, F024, and F25 are target formulations of center point batches.

\section{RESULTS}

Atazanavir sulfate and ritonavir are biopharmaceutical classification systems (BCS) class II and class IV compounds, respectively, with low solubility. Atazanavir sulfate is officially in the international pharmacopeia; ritonavir is official in United States pharmacopoeia (USP) and international pharmacopeia. The drug product, atazanavir, and ritonavir tablets, are not officially in any of the pharmacopeia. Hence, the dissolution method of 0.025 NHCL+0.06 M POE10LE was selected based on the solubility studies of both active substances and patent literature studies. Hence, the studied design of experiments (DOE) batches was performed in the dissolution media to understand the significant differences of formulation variables of both layers. Table 5 and table 6 indicates dissolution is the main response.

Table 5: Factors and response of design of experiments (DoE) design for the ritonavir intragranular formulation (Layer-I)

\begin{tabular}{llllll}
\hline Batch No. & Standard & Run & Factor 1A: Span 20 (mg) & Factor 2B: aer osil (mg) & Response 1: Dissolution of ritonavir at 120 min (\%) \\
\hline F12 & 5 & 2 & 60 & 8 & $92 \pm 0.78$ \\
F13 & 2 & 1 & 80 & 0 & $98 \pm 0.68$ \\
F14 & 4 & 3 & 80 & 16 & $98 \pm 0.42$ \\
F15 & 3 & 4 & 40 & 16 & $82 \pm 1.20$ \\
F16 & 1 & 5 & 40 & 0 & $84 \pm 0.82$ \\
F17 & 6 & 6 & 60 & 8 & $95 \pm 0.34$ \\
F18 & 7 & 7 & 60 & 8 & $95 \pm 0.58$ \\
\hline
\end{tabular}

*Data given in mean \pm SD.

Table 6: Factors and response of design of experiments (DOE) for the atazanavir intragranular formulation (Layer-II)

\begin{tabular}{llllll}
\hline Batch No. & Standard & Run & Factor 1A: Starch1500 (mg) & $\begin{array}{l}\text { Factor 2B: crospovidone } \\
\text { (mg) }\end{array}$ & $\begin{array}{l}\text { Response 1: dissolution of atazanavir at 120 } \\
\text { min (\%)* }\end{array}$ \\
\hline F19 & 3 & 1 & 5 & 5 & $96 \pm 0.26$ \\
F20 & 5 & 2 & 25 & 5 & $97 \pm 1.40$ \\
F21 & 1 & 3 & 5 & 25 & $97 \pm 0.68$ \\
F22 & 4 & 4 & 25 & 25 & $97 \pm 0.89$ \\
F23 & 6 & 5 & 15 & 15 & $96 \pm 1.60$ \\
F24 & 2 & 6 & 15 & 15 & $98 \pm 0.42$ \\
F25 & 7 & 7 & 15 & 15 & $97 \pm 1.20$ \\
\hline
\end{tabular}

${ }^{*}$ Data given in mean $\pm \mathrm{SD}$

The dissolution method was tested using the in-house method. All the batches were meeting $Q$ point of the dissolution $(Q>80 \%$ dissolved in $120 \mathrm{~min}$ ); since center points were included in the design of experiments (DOE), the significance of the curvature effect was tested using an adjusted model. Analysis of variance (ANOVA) analysis represents whether a model and factor are significant for the respective response or not. It is concluded to be significant if the $\mathrm{p}$-value were below the threshold $(\mathrm{p}=0.05)$. The analysis of variance (ANOVA) results are presented below and it defines the formulation variables are significant or not on the final product.

Table 7: Analysis of variance (ANOVA) results of the model adjusted for curvature effect (Layer-I)

\begin{tabular}{|c|c|c|c|c|c|c|c|}
\hline Response & Source & Sum of squares & df & Mean square & F value & P-value* & Comments \\
\hline Diss. in & Model & 227.00 & 3 & 75.67 & 25.22 & 0.0384 & Significant \\
\hline $0.025 \mathrm{~N}$ & A-Sorbitan monolaurate & 225.00 & 1 & 225.00 & 75.00 & 0.0131 & Significant \\
\hline HCL+ & B-Colloidal silicon dioxide & 1.00 & 1 & 1.00 & 0.3333 & 0.6220 & Not significant \\
\hline $0.06 \mathrm{M}$ & $\mathrm{AB}$ & 1.00 & 1 & 1.00 & 0.3333 & 0.6220 & Not significant \\
\hline POE & Curvature & 21.00 & 1 & 21.00 & 7.00 & 0.1181 & Not significant \\
\hline \multirow[t]{2}{*}{$10 \mathrm{LE}$} & Pure error & 6.00 & 2 & 3.00 & - & - & - \\
\hline & CorTotal & 254.00 & 6 & - & - & - & - \\
\hline
\end{tabular}

${ }^{*} \mathrm{P}$-value less than 0.0500 indicate above model terms and factor-A are significant 
Table 8: Analysis of variance (ANOVA) results of the model adjusted for curvature effect (Layer-II)

\begin{tabular}{llllllll}
\hline Response & Source & Sum of squares & df & Mean square & F value & P-value $^{*}$ \\
\hline Diss. in & Model & 0.7500 & 3 & 0.2500 & 0.2500 & 0.8576 \\
0.025 N & A-Starch1500 & 0.2500 & 1 & 0.2500 & 0.2500 & 0.6667 \\
HCL+ & B-Crospovidone & 0.2500 & 1 & 0.2500 & 0.2500 & 0.6667 \\
0.06 M & AB & 0.2500 & 1 & 0.2500 & 0.2500 & 0.6667 & Significant \\
POE & Curvature & 0.1071 & 1 & 0.1070 & 0.1070 & 0.7745 & Not significant \\
10LE & Pure error & 2.00 & 2 & 1.0000 & - & - & Not significant \\
& Cor Total & 2.86 & 6 & - & - & - \\
\hline
\end{tabular}

${ }^{*} \mathrm{P}$-value less than 0.0500 indicate above model terms are significant

Based on the analysis of variance (ANOVA) results for ritonavir (Layer-I), the model and sorbitan monolaurate showed a significant impact on the dissolution, and the P-value was observed less than 0.0500. Colloidal silicon dioxide has no impact on the dissolution and curvature and interaction of both factors is also observed to be not significant. The overlay plot indicates that the green zone is found to be within the specification limit and the grey zone indicates a failure to meet the specification. Further, the half-normal plot and contour plot also represents sorbitan monolaurate has a significant impact on the dissolution. Hence, sorbitan monolaurate in the formulation is recommended to 47 to $80 \mathrm{mg}$ from $40-80 \mathrm{mg} / \mathrm{tablet}$ for controlling the consistency of finished product dissolution results. Atazanavir sulfate (layer-II), model showed no significant impact on the dissolution, and P-value was also observed at more than 0.0500. It indicates that the studied range of both factors has no significant impact on the dissolution and all the results were found to be well within the limit. Hence the overlay plot showed all the green.
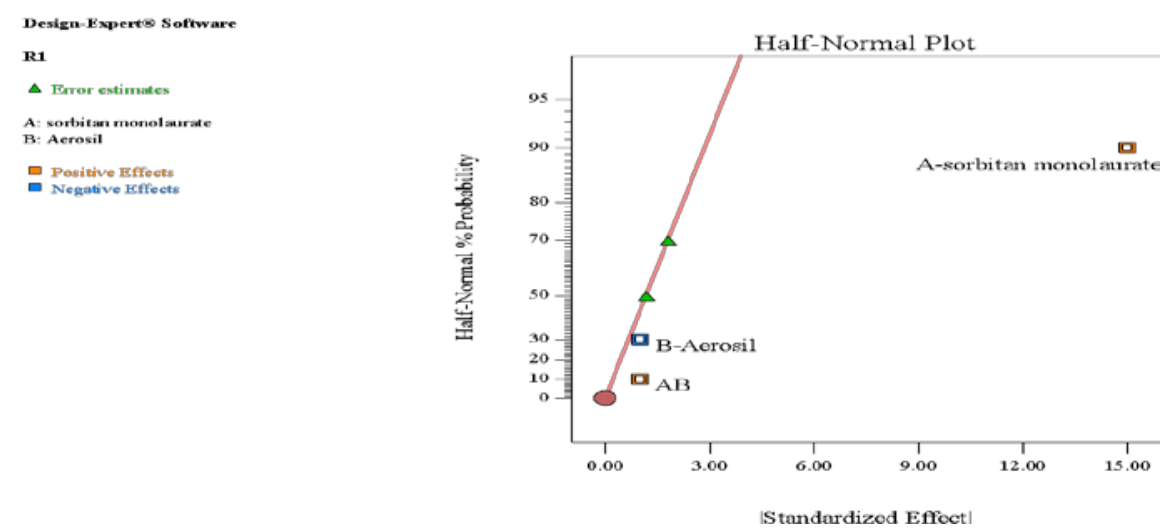

Fig. 2: The half-normal plot of the formulation variable effects on dissolution rate (Layer-I)
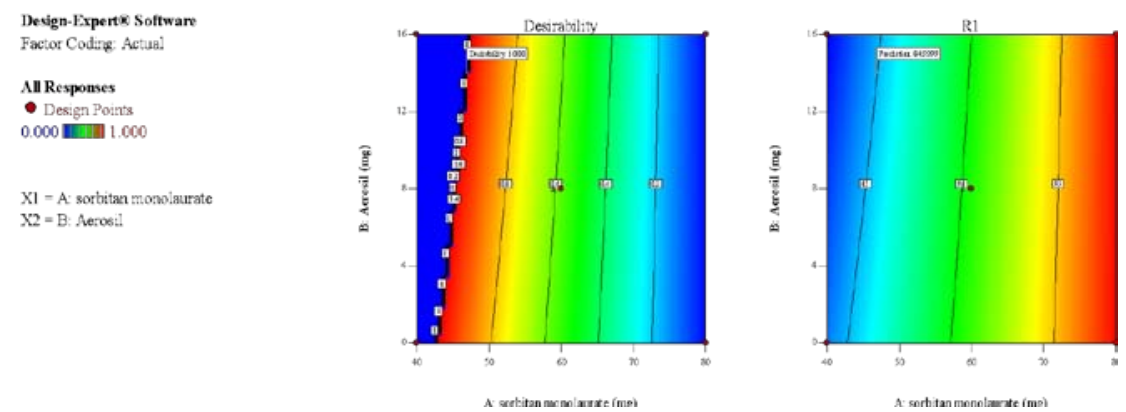

Fig. 3: Contour plot of the formulation variables on dissolution (Layer-I)
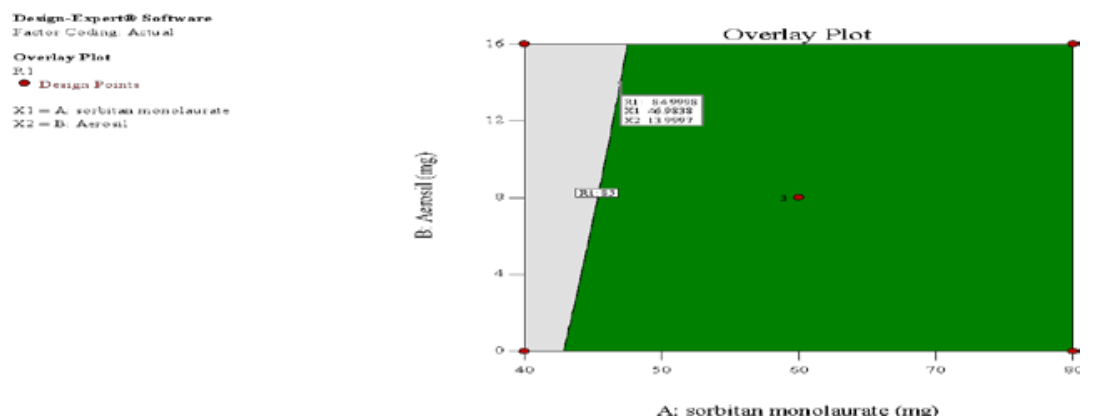

Fig. 4: Overlay plot-effect of formulation variables on responses (Layer-I) 

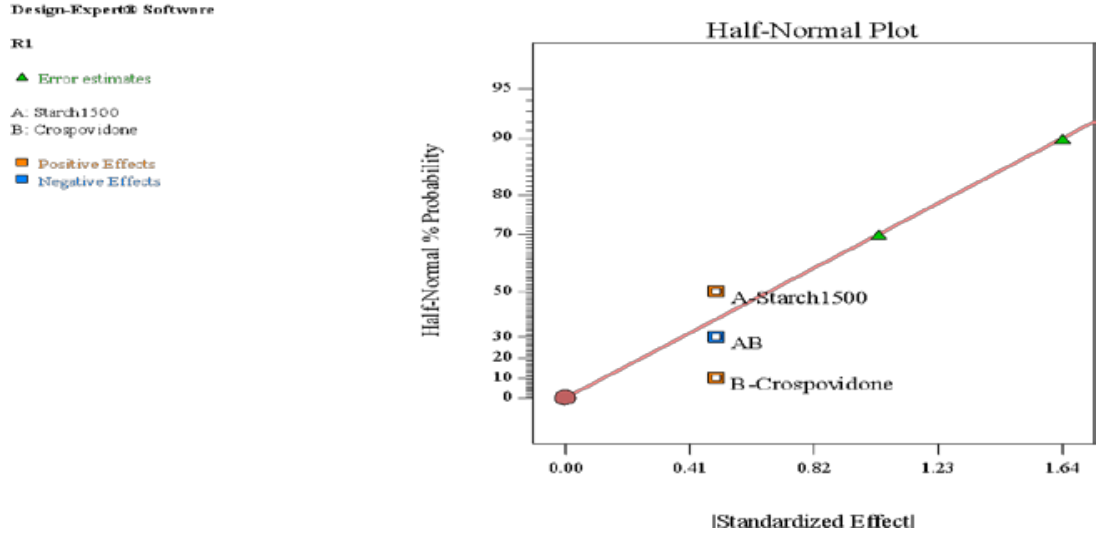

Fig. 5: The half-normal plot of the formulation variable effects on dissolution rate (Layer-II)
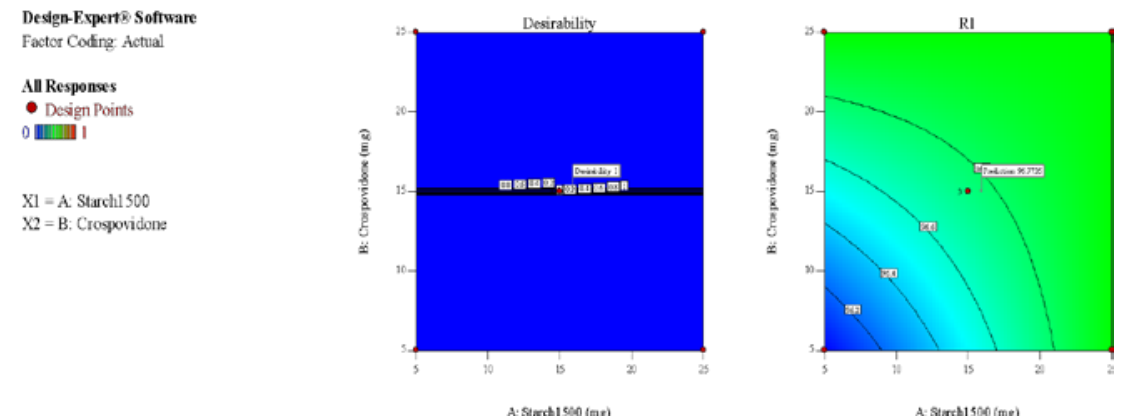

Fig. 6: Contour plot of the formulation variables on dissolution (Layer-II)
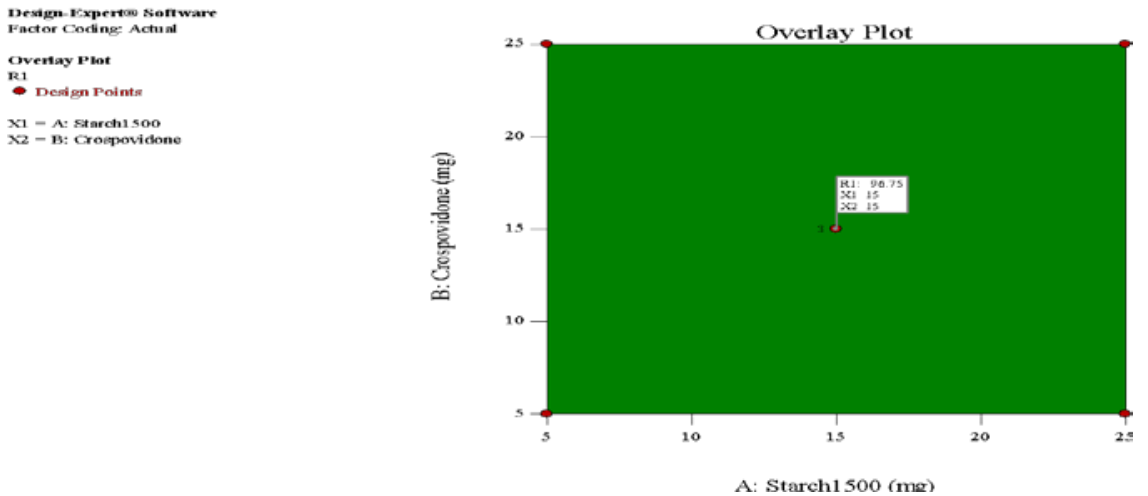

Fig. 7: Overlay plot-effect of formulation variables on responses (Layer-II)

Hot-melt extrusion process optimization of layer-I(ritonavir part)

The hot-melt extrusion process is a critical step in the manufacturing of robust products and needs optimization of the process. Center point batches of ritonavir target formulation (F12, F17 and F18) as per table 3 were considered for the process optimization. Risk assessment of the manufacturing process was carried out and the design of experiments (DOE) was designed for the parameters as mentioned in table 9 .
Ritonavir part process variables in hot-melt extrusion like temperature, feed rate, and screw rotate per minute (RPM) were studied in higher and lower levels, including center points to evaluate related substance effect on drug effect. For the design of experiments (DOE) interpretations of related substances, only the highest unknown impurity levels were considered as a response as the other impurities were observed well within the limit. Hence the impurities other than the highest unknown are considered as low risk.

Table 9: Variables (Levels and constraints) for ritonavir hot-melt extrusion process

\begin{tabular}{lll}
\hline Independent variables & Different levels & Medium \\
\cline { 2 - 3 } & Low & High \\
\hline Temperature (C) & 105 & 120 \\
Feed rate (g/min) & 20 & 25 \\
Screw speed (RPM) & 125 & 175 \\
Response & Goal & Acceptable Range \\
Maximum unknown impurity & Minimize & NMT0.200\% \\
Diss. in 0.025 N HCL+0.06 MP0E10LE & Maximize & NLT85 (Q)at 120 min. \\
\hline
\end{tabular}


In the hot-melt extrusion process, the variation in temperature, feeding rate, and screw speed have an impact on the degradation of the product. Which indirectly affects the assay. Hence the risk on the assay and related substances is high. Solid dispersion takes place in a hot-melt extrusion process and it increases the dissolution of the drug product. The hot-melt extrusion (HME) parameters such as temperature, screw rotate per minute (RPM) and feeding rate have an impact on solid dispersion. Hence, the risk is high. All the responses were fitted to linear, interaction, or quadratic models using design expert version.11. Stat-Ease
Minneapolis USA and analyzed statistically using analysis of variance (ANOVA) and those are having a p-value less than 0.05 were included in the analysis. The data were also subjected to 3-D response surface methodology to study the interaction of process parameters and their effects on dependent variables. Thus, from the design of experiments (DOE) data, the design space was constructed within the acceptable limit. Hence, full factorial design 2 level, three factors with 3 center points were selected for the design of experiments (DOE) evaluation of the hot-melt extrusion process as per table 10 .

Table 10: Factors and responses for the ritonavir hot-melt extrusion (HME) process optimization

\begin{tabular}{|c|c|c|c|c|c|c|c|}
\hline $\begin{array}{l}\text { Batch } \\
\text { No. }\end{array}$ & Std. & Run & $\begin{array}{l}\text { Factor } 1 \\
\text { A: temperature } \\
\text { (C) }\end{array}$ & $\begin{array}{l}\text { Factor } 2 \\
\text { B: feed rate } \\
(\mathrm{g} / \mathrm{min}) \\
\end{array}$ & $\begin{array}{l}\text { Factor } 3 \\
\text { C: screw speed } \\
\text { (RPM) }\end{array}$ & $\begin{array}{l}\text { Response } 1 \text { RS (\%): } \\
\text { highest unknown limit: } \\
\text { NMT } 0.200 \%\end{array}$ & $\begin{array}{l}\text { Response } 2 \text { dissolutions at } 120 \\
\text { min limit: NLT85(Q) at } 120 \\
\text { min* }\end{array}$ \\
\hline F26 & 10 & 1 & 120 & 25 & 175 & 0.077 & $99 \pm 0.59$ \\
\hline F27 & 5 & 2 & 105 & 20 & 225 & 0.111 & $95 \pm 0.85$ \\
\hline F28 & 9 & 3 & 120 & 25 & 175 & 0.063 & $99 \pm 0.77$ \\
\hline F29 & 4 & 4 & 135 & 30 & 125 & 0.195 & $96 \pm 0.74$ \\
\hline F30 & 8 & 5 & 135 & 30 & 225 & 0.19 & $99 \pm 0.98$ \\
\hline F31 & 6 & 6 & 135 & 20 & 225 & 0.186 & $101 \pm 0.68$ \\
\hline F32 & 2 & 7 & 135 & 20 & 125 & 0.204 & $100 \pm 0.75$ \\
\hline F33 & 11 & 8 & 120 & 25 & 175 & 0.063 & $98 \pm 1.40$ \\
\hline F34 & 1 & 9 & 105 & 20 & 125 & 0.045 & $99 \pm 0.96$ \\
\hline F35 & 3 & 10 & 105 & 30 & 125 & 0.07 & $101 \pm 0.85$ \\
\hline F36 & 7 & 11 & 105 & 30 & 225 & 0.045 & $100 \pm 0.88$ \\
\hline
\end{tabular}

$*$ Data given in mean \pm SD
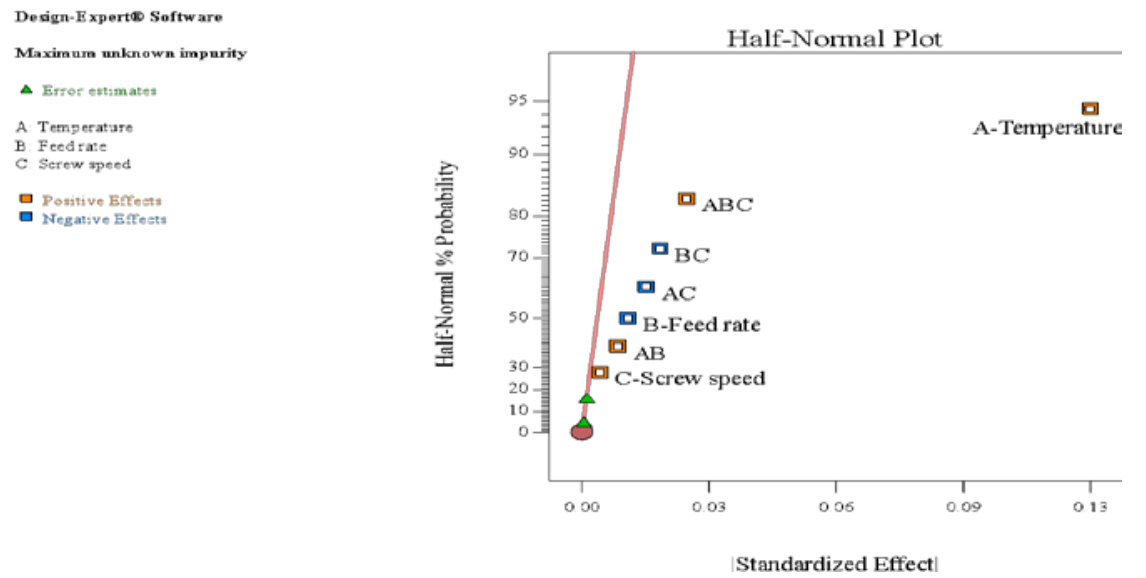

Fig. 8: The half-normal plot of the hot-melt extrusion (HME) process variable effects on related substances (Layer-I)
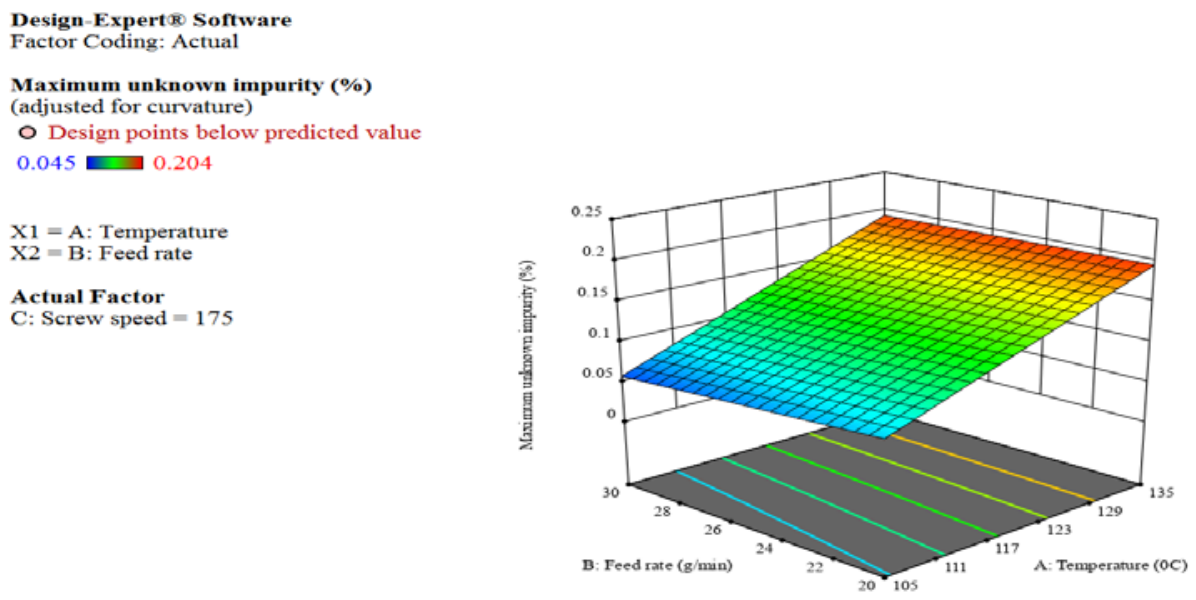

Fig. 9: 3D surface plot of the hot-melt extrusion (HME) process variable effects on related substances (Layer-I) 
Table 11: Factors and response of design of experiments (DOE) for the ritonavir hot-melt extrusion (HME) process optimization

\begin{tabular}{|c|c|c|c|c|c|c|c|}
\hline Response & Source & Sum of squares & df & Mean square & F value & P-value* & Comments \\
\hline RS (\%): & Model & 0.0348 & 7 & 0.0050 & 76.19 & 0.0130 & Significant \\
\hline Highest & A-Temperature & 0.0318 & 1 & 0.0318 & 486.00 & 0.0021 & Significant \\
\hline unknown & B-Feed rate & 0.0003 & 1 & 0.0003 & 4.05 & 0.1819 & Not significant \\
\hline impurity Limit: & C-Screw speed & 0.0000 & 1 & 0.0000 & 0.6199 & 0.5136 & Not significant \\
\hline \multirow[t]{7}{*}{ NMT0.200\% } & $\mathrm{AB}$ & 0.0002 & 1 & 0.0002 & 2.48 & 0.2560 & Not significant \\
\hline & AC & 0.0005 & 1 & 0.0005 & 7.84 & 0.1074 & Not significant \\
\hline & $\mathrm{BC}$ & 0.0008 & 1 & 0.0008 & 11.64 & 0.0762 & Not significant \\
\hline & $\mathrm{ABC}$ & 0.0014 & 1 & 0.0014 & 20.69 & 0.0551 & Not significant \\
\hline & Curvature & 0.0087 & 1 & 0.0087 & 132.90 & 0.0574 & Not significant \\
\hline & Pure error & 0.0001 & 2 & 0.0001 & - & - & - \\
\hline & Total & 0.0137 & 10 & - & - & - & - \\
\hline
\end{tabular}

${ }^{*} \mathrm{P}$-value less than 0.0500 indicate above model terms and factor-A are significant
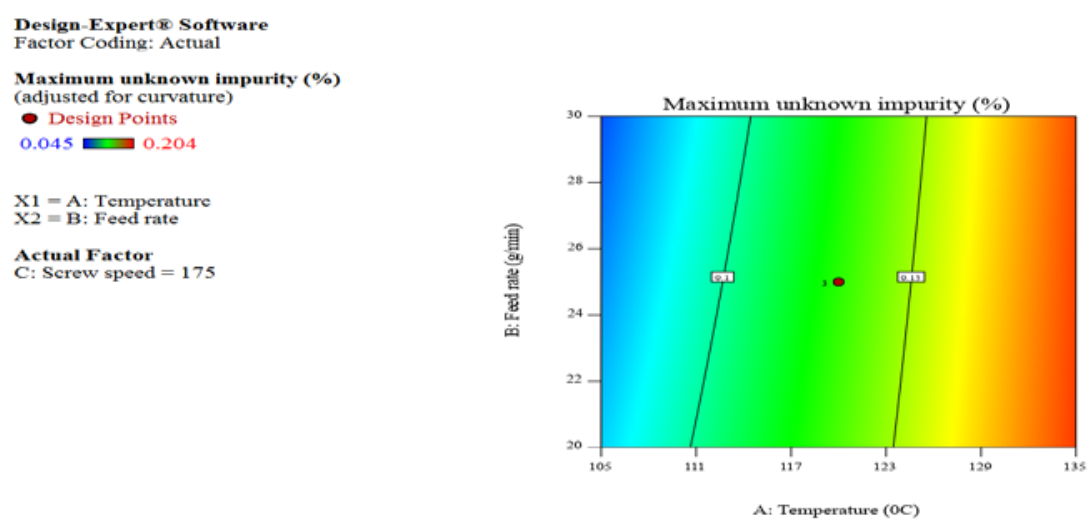

Fig. 10: Contour plot of the hot-melt extrusion (HME) process variable effects on related substances (Layer-I)

Table 12: Factors and response of design of experiments (DOE) design for the ritonavir hot-melt extrusion process

\begin{tabular}{|c|c|c|c|c|c|c|c|}
\hline Response & Source & Sum of squares & df & Mean square & F value & P-value* & Comments \\
\hline Diss. in $0.025 \mathrm{~N}$ & Model & 34.88 & 7 & 4.98 & 14.95 & 0.0641 & not significant \\
\hline HCL+ & A-Temperature & 0.1250 & 1 & 0.1250 & 0.3750 & 0.6026 & not significant \\
\hline $0.06 \mathrm{M}$ & B-Feed rate & 0.1250 & 1 & 0.1250 & 0.3750 & 0.6026 & not significant \\
\hline POE & C-Screw speed & 0.1250 & 1 & 0.1250 & 0.3750 & 0.6026 & not significant \\
\hline $10 \mathrm{LE}$ & $\mathrm{AB}$ & 21.13 & 1 & 21.13 & 63.38 & 0.0154 & Significant \\
\hline Limit: & $\mathrm{AC}$ & 10.12 & 1 & 10.12 & 30.37 & 0.0314 & Significant \\
\hline NLT 80(Q) & $\mathrm{BC}$ & 3.12 & 1 & 3.12 & 9.37 & 0.0922 & not significant \\
\hline \multirow[t]{4}{*}{ At $120 \mathrm{~min}$} & $\mathrm{ABC}$ & 0.1250 & 1 & 0.1250 & 0.3750 & 0.6026 & not significant \\
\hline & Curvature & 0.0947 & 1 & 0.0947 & 0.2841 & 0.6473 & not significant \\
\hline & Pure Error & 0.6667 & 2 & 0.3333 & - & - & - \\
\hline & Cor total & 35.64 & 10 & - & - & - & - \\
\hline
\end{tabular}

${ }^{*} \mathrm{P}$-value less than 0.0500 indicate above model terms and interaction factors-AB and AC are significant
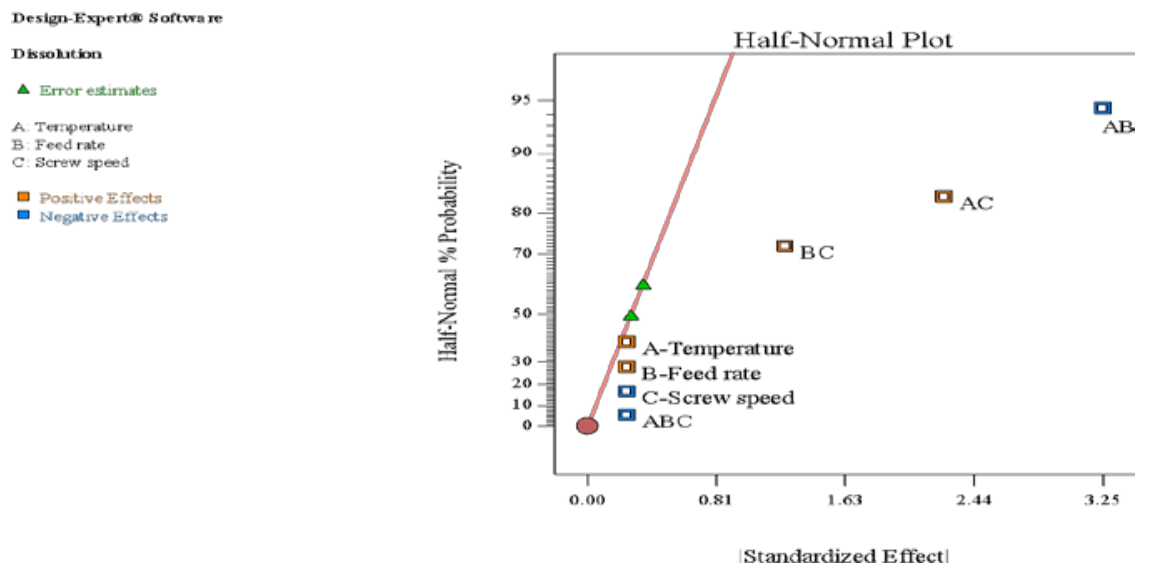

Fig. 11: Half normal plot of the hot-melt extrusion (HME) process variable effects on dissolution (Layer-I) 

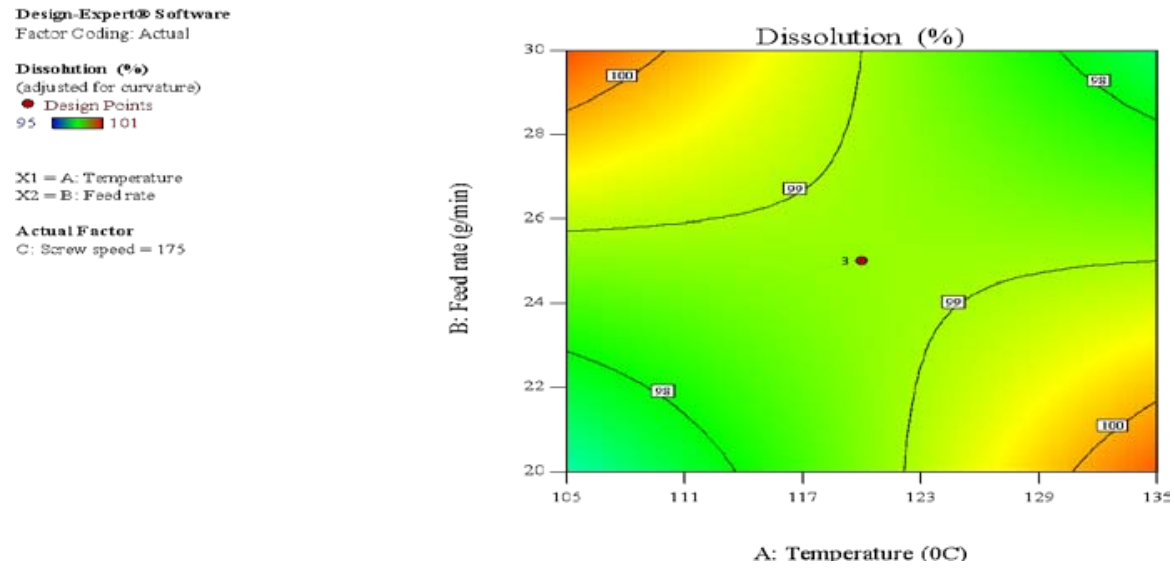

Fig. 12: Contour plot of the hot-melt extrusion (HME) process variable effects on dissolution (Layer-I)
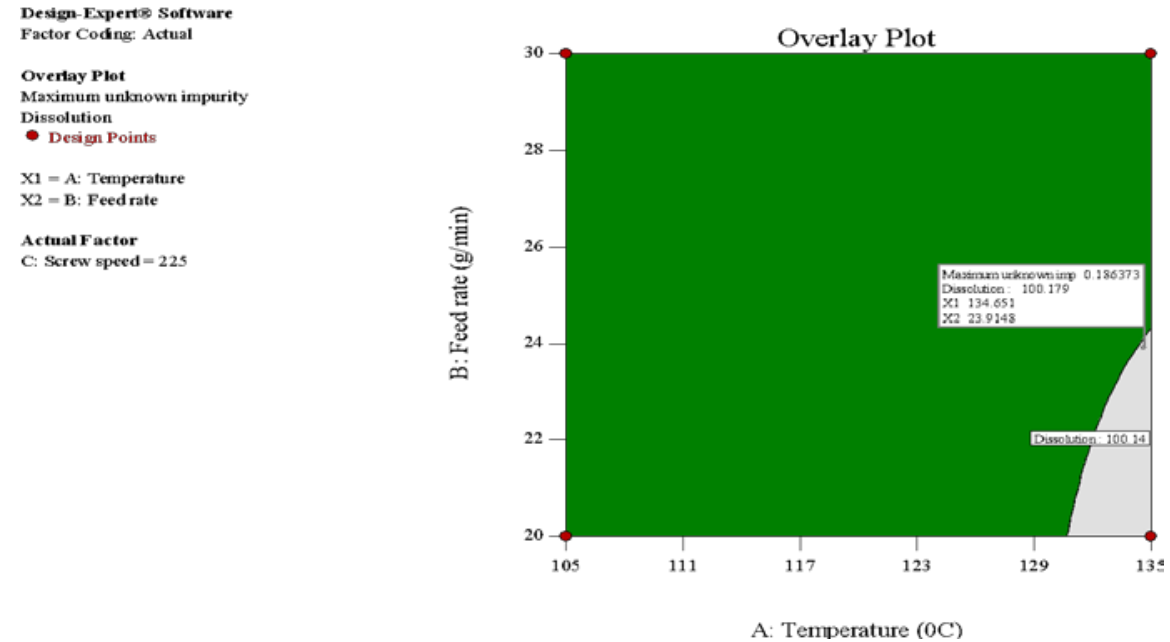

Fig. 13: Overlay plot of the hot-melt extrusion (HME) process variable effects on dissolution and related substances (Layer-I)

Based on the evaluation of analysis of variance (ANOVA) responses, the highest unknown impurity observed to be failure meets the specification with Factor-A (Temperature) during the extrusion process. As per the half-normal plot, 3D surface plot, and contour plot, temperature plays an important role in controlling the unknown impurities within the limit. Temperature above $130{ }^{\circ} \mathrm{C}$ along with feeder rate from $20-24(\mathrm{~g} / \mathrm{min})$ has been removed from the design of experiments (DOE) range and it was found to be a failure to meet the maximum unknown impurity limit.

As per the design of experiments (DOE) studies, these three factors had no significant impact on the dissolution of finished products even though interaction factors $A B$ and $A C$ showed significance in the Analysis of variance (ANOVA). As per the above overlay plot, the green zone indicates all the responses meet the specification limits well within the limit. Grey zone indicates a failure to meet the specification limits. Because no curvature effects were observed for any of the responses studied using full factorial design of experiments (DOE), further studies to optimize the ritonavir part process were unnecessary.

Based on the process design of experiments (DOE) study for the ritonavir part, a feed rate of $25-30 \mathrm{~g} / \mathrm{min}$ and a temperature range from $105-130{ }^{\circ} \mathrm{C}$ can be recommended to control the responses of maximum unknown impurity and dissolution results well within the limit.

\section{Wet granulation process optimization of Layer-II (Atazanavir sulfate)}

The formulation design for Layer-II by wet granulation with purified water used as the granulating solvent. Granulation process parameters such as binder addition time, fluid uptake, impeller and chopper speed, kneading time, wet milling, and dry milling screen size, and mill speed are considered as critical parameters as part of the risk assessment for the granulation process. But, all these parameters have no significant impact on the dissolution at $15 \mathrm{~min}$ and it was observed more than $85 \%$ for all the batches in the recommended dissolution media. However, fluid uptake, impeller speed, and kneading time resulted to be variation for dissolution at $5 \mathrm{~min}$ and $10 \mathrm{~min}$ dissolution comparatively with target granulation process parameters. The wet granulation process has no significance on the dissolution of the drug product in the selected dissolution media at 15 min. Hence, process parameters were used for the wet granulation process for Layer-II were not considered for the optimization study.

The factorial batches were prepared using the design of experiments (DOE) for the hot-melt extrusion process for tablet properties observed to comply with the acceptable limits. Parle elizabeth with a lab model of a bilayer compression machine was used for the compression. Ritonavir part (layer-I) was used as the first layer and compression parameters were set as per table 13. After setting the first layer, atazanavir sulfate (layer-II) was loaded into the hopper for second layer compression, and other compression parameters such as feeder speed, fill depth, pre-compression force, main compression force was maintained for the optimum physical parameters such as hardness, thickness, disintegration time, friability, and physical appearance.

As per table 13, design of experiments (DOE) batches from F026 to F36, all the physical parameters are found to comply during the execution of compression. In which disintegration time for layer-I 
and layer-II were monitored and layer-I was observed about 5-7 min and layer-II was observed around 29-36 min. All the studied batches for dissolution were found to comply well within the acceptable limits and comparable with each reference product. Based on the evaluation of dissolution results in table 10, there are no significant differences among all the batches and consistent within the studied hardness range of $16-28 \mathrm{~N}$ at the recommended dissolution time point of $120 \mathrm{~min}$.

Table 13: Compression parameters and physical parameters of the core tablets

\begin{tabular}{|c|c|c|c|c|c|c|c|c|c|c|c|c|}
\hline Parameters * & & F26 & F27 & F28 & F29 & F30 & F31 & F32 & F33 & F34 & F35 & F36 \\
\hline Turret speed & & 10 & & & & & & & & & & \\
\hline \multirow{2}{*}{$\begin{array}{l}\text { Feeder speed } \\
\text { (RPM) }\end{array}$} & S1 & \multicolumn{11}{|c|}{7 (Ritonavir part) } \\
\hline & S2 & \multicolumn{11}{|c|}{5 (Atazanavir sulfate part) } \\
\hline \multirow[t]{3}{*}{$\begin{array}{l}\text { Fill depth } \\
(\mathrm{mm})\end{array}$} & S1 & $\begin{array}{l}5.15 \pm 0 . \\
5\end{array}$ & $\begin{array}{l}5.15 \pm 0 . \\
3\end{array}$ & $\begin{array}{l}5.17 \pm 0 . \\
8\end{array}$ & $\begin{array}{l}5.21 \pm 0 . \\
7\end{array}$ & $\begin{array}{l}5.17 \pm 0 . \\
8\end{array}$ & $\begin{array}{l}5.17 \pm 0 . \\
4\end{array}$ & $\begin{array}{l}5.16 \pm 0 . \\
7\end{array}$ & $\begin{array}{l}5.15 \pm 0 . \\
4\end{array}$ & $\begin{array}{l}5.19 \pm 0 . \\
6\end{array}$ & $\begin{array}{l}5.14 \pm 0 . \\
6\end{array}$ & $\begin{array}{l}5.15 \pm 0 \text {. } \\
9\end{array}$ \\
\hline & S2 & $11.90 \pm$ & $11.98 \pm$ & $12.10 \pm$ & $11.78 \pm$ & $12.10 \pm$ & $11.98 \pm$ & $11.98 \pm$ & $11.90 \pm$ & $11.96 \pm$ & $11.98 \pm$ & $12.46 \pm$ \\
\hline & & 0.3 & 0.5 & 0.6 & 0.2 & 0.3 & 0.6 & 0.6 & 0.8 & 0.6 & 0.8 & 0.2 \\
\hline \multirow{4}{*}{$\begin{array}{l}\text { PCF position } \\
\text { (mm) } \\
\text { MCF position } \\
(\mathrm{mm})\end{array}$} & S1 & 3.2 & 3.3 & 3.4 & 3.6 & 3.3 & 3.4 & 3.6 & 3.2 & 3.2 & 3.3 & 3.2 \\
\hline & $\mathrm{S} 2$ & 4.9 & 4.5 & 4.8 & 4.6 & 4.8 & 5.1 & 5.2 & 4.9 & 4.9 & 4.8 & 5.2 \\
\hline & $\mathrm{S} 1$ & 8.4 & 8.4 & 8.5 & 8.9 & 8.6 & 8.2 & 8.2 & 8.4 & 8.2 & 8.3 & 9.8 \\
\hline & $\mathrm{S} 2$ & 4.0 & 4.2 & 4.3 & 4.2 & 4.2 & 3.9 & 4.9 & 4.1 & 4.1 & 4.2 & 4.6 \\
\hline Average force & S1 & 3.10 & 3.12 & 3.80 & 3.16 & 3.14 & 3.16 & 3.20 & 3.10 & 3.60 & 4.10 & 3.70 \\
\hline of PCF(kN) & S2 & 4.10 & 4.60 & 4.20 & 4.30 & 4.28 & 4.50 & 4.18 & 4.10 & 4.10 & 4.20 & 5.80 \\
\hline Average force & S1 & 0.00 & 0.00 & 0.00 & 0.00 & 0.00 & 0.00 & 0.00 & 0.00 & 0.00 & 0.00 & 0.00 \\
\hline \multirow[t]{2}{*}{ of $\mathrm{MCF}(\mathrm{kN})$} & $\mathrm{S} 2$ & $16.05 \pm$ & $17.05 \pm$ & $16.35 \pm$ & $16.71 \pm$ & $16.05 \pm$ & $16.45 \pm$ & $16.35 \pm$ & $16.05 \pm$ & $18.05 \pm$ & $17.05 \pm$ & $18.21 \pm$ \\
\hline & & 0.25 & 1.25 & 0.95 & 0.71 & 0.85 & 2.65 & 0.55 & 0.25 & 1.25 & 2.25 & 0.40 \\
\hline \multirow{3}{*}{$\begin{array}{l}\text { Weight } \\
\text { variance }\end{array}$} & Avg & 1605.0 & 1602.0 & 1596.0 & 1610.0 & 1604.0 & 1611.0 & 1590.0 & 1601.0 & 1594.0 & 1600.0 & 1602.0 \\
\hline & & \pm & \pm & \pm & \pm & \pm & \pm & \pm & \pm & \pm & \pm & \pm \\
\hline & & 1.20 & 1.62 & 0.43 & 1.24 & 2.24 & 1.82 & 1.42 & 1.30 & 0.82 & 2.48 & 1.99 \\
\hline \multirow{3}{*}{$\begin{array}{l}\text { Hardness } \\
\text { range (kP) } \\
\text { Thickness } \\
(\mathrm{mm})\end{array}$} & $16-$ & $20.90 \pm$ & $20.90 \pm$ & $20.0 \pm$ & $21.20 \pm$ & $22.00 \pm$ & $20.70 \pm$ & $21.00 \pm$ & $21.00 \pm$ & $21.00 \pm$ & $20.00 \pm$ & $23.00 \pm$ \\
\hline & $28 \mathrm{kP}$ & 1.95 & 2.0 & 2.2 & 2.80 & 1.8 & 2.1 & 3.0 & 2.2 & 2.85 & 2.2 & 1.8 \\
\hline & $\begin{array}{l}8.00- \\
8.60 \\
\mathrm{~mm}\end{array}$ & $\begin{array}{l}8.34 \pm 0 . \\
1\end{array}$ & $\begin{array}{l}8.32 \pm 0 . \\
2\end{array}$ & $\begin{array}{l}8.34 \pm 0 . \\
1\end{array}$ & $\begin{array}{l}8.28 \pm 0 . \\
2\end{array}$ & $\begin{array}{l}8.31 \pm 0 . \\
2\end{array}$ & $\begin{array}{l}8.36 \pm 0 . \\
1\end{array}$ & $\begin{array}{l}8.32 \pm 0 . \\
2\end{array}$ & $\begin{array}{l}8.31 \pm 0 . \\
2\end{array}$ & $\begin{array}{l}8.32 \pm 0 . \\
2\end{array}$ & $\begin{array}{l}8.34 \pm 0 . \\
2\end{array}$ & $\begin{array}{l}8.28 \pm 0 \\
2\end{array}$ \\
\hline \multirow{4}{*}{$\begin{array}{l}\text { Disintegration } \\
\text { time (min/sec) }\end{array}$} & Atazan & $6 \min$ & $6 \mathrm{~min}$ & $6 \mathrm{~min}$ & $5 \min$ & $6 \mathrm{~min}$ & $6 \min$ & $6 \mathrm{~min}$ & $6 \min$ & $6 \min$ & $7 \mathrm{~min}$ & $5 \mathrm{~min}$ \\
\hline & $\begin{array}{l}\text { avir: } \\
\text { NMT15 } \\
\text { min }\end{array}$ & $15 \mathrm{sec}$ & $15 \mathrm{sec}$ & $50 \mathrm{sec}$ & $55 \mathrm{sec}$ & $45 \mathrm{sec}$ & $20 \mathrm{sec}$ & $15 \mathrm{sec}$ & $15 \mathrm{sec}$ & $15 \mathrm{sec}$ & $15 \mathrm{sec}$ & $55 \mathrm{sec}$ \\
\hline & Ritona & $35 \mathrm{~min}$ & $38 \mathrm{~min}$ & $32 \mathrm{~min}$ & $34 \mathrm{~min}$ & $36 \mathrm{~min}$ & $29 \mathrm{~min}$ & $35 \mathrm{~min}$ & $35 \mathrm{~min}$ & $35 \mathrm{~min}$ & $35 \mathrm{~min}$ & $36 \mathrm{~min}$ \\
\hline & $\begin{array}{l}\text { vir: } \\
\text { NMT60 } \\
\min \end{array}$ & $20 \mathrm{sec}$ & $20 \mathrm{sec}$ & $20 \mathrm{sec}$ & $20 \mathrm{sec}$ & $20 \mathrm{sec}$ & $20 \mathrm{sec}$ & $20 \mathrm{sec}$ & $20 \mathrm{sec}$ & $20 \mathrm{sec}$ & $15 \mathrm{sec}$ & $20 \mathrm{sec}$ \\
\hline \multirow[t]{2}{*}{ Friability } & NMT1. & $0.4 \pm 0.0$ & $0.4 \pm 0.0$ & $0.4 \pm 0.0$ & $0.4 \pm 0.0$ & $0.4 \pm 0.0$ & $0.4 \pm 0.0$ & $0.4 \pm 0.0$ & $0.4 \pm 0.0$ & $0.4 \pm 0.0$ & $0.4 \pm 0.0$ & $0.4 \pm 0.0$ \\
\hline & $0 \%$ & 1 & 2 & 1 & 2 & 2 & 2 & 1 & 1 & 1 & 2 & 1 \\
\hline
\end{tabular}

*Data given in mean \pm SD, Based on the evaluation of formulation and process optimization, the final formulation in table 14 was recommended for stability.

Tablet 14: Proposed formulation for stability studies

\begin{tabular}{|c|c|c|}
\hline S. No. & Ingredients & Mg/tab \\
\hline 1 & Atazanavir sulfate & 341.7 \\
\hline 2 & Lactose monohydrate & 152.0 \\
\hline 3 & Starch 1500 & 15.0 \\
\hline 4 & Crospovidone & 15.0 \\
\hline 5 & water & Q.S \\
\hline \multicolumn{3}{|c|}{ Extra granular } \\
\hline 5 & Starch 1500 & 50.0 \\
\hline 6 & Crospovidone & 50.0 \\
\hline 7 & Calcium silicate & 40.0 \\
\hline 8 & Ferric oxide yellow & 0.5 \\
\hline 9 & Magnesium stearate & 5.8 \\
\hline \multicolumn{2}{|c|}{ Total weight of Atazanavir layer } & 670.0 \\
\hline 10 & Ritonavir & 100.0 \\
\hline 11 & Co povidone & 585.0 \\
\hline 12 & Sorbitan monolaurate & 60.0 \\
\hline 13 & Colloidal silicon dioxide & 8.0 \\
\hline \multicolumn{3}{|c|}{ Extra granular } \\
\hline 14 & Dicalcium phosphate anhydrous & 110.0 \\
\hline 15 & Colloidal silicon dioxide & 20.0 \\
\hline 16 & Sodium stearyl fumarate & 7.0 \\
\hline \multicolumn{2}{|c|}{ Total weight of ritonavir layer } & 890.0 \\
\hline \multicolumn{2}{|c|}{ Total weight of core tab } & 1560.0 \\
\hline 17 & Opadry II yellow & 40.00 \\
\hline 18 & Purified water & Q.S \\
\hline \multicolumn{2}{|c|}{ Total weight of coated tab } & 1600.00 \\
\hline
\end{tabular}


Drug release is usually the rate-limiting process for absorption of the biopharmaceutical classification system (BCS) class II and class IV compounds due to their low solubility. Atazanavir sulfate is a biopharmaceutical classification system (BCS) class II, drug and ritonavir is a class IV drug. Therefore, the dissolution of the reference product was compared with a fixed-dose formulation in the in-house dissolution media of $0.025 \mathrm{NHCL}+0.06$ MPOE10LE, volume: $900 \mathrm{ml}$ apparatus type I, agitation speed 100 rotate per minute (RPM). Dissolution media was selected based on patent research data and the solubility of both active substances such as ritonavir and atazanavir sulfate.

As per fig. 14, the formulation study of batches from F15 and F16 contains $40 \mathrm{mg}$ of span 20 with aerosol and without aerosil and the dissolution rate resulted as low. Batches from F12 and F13 contain $80 \mathrm{mg}$ of span 20 with aerosil and without aerosil indicates a high dissolution rate. But, center point batches of F12, F17, and F18 results were found to be optimum and comparable with the reference drugs. As per fig. 15, the formulation study of batches from F19 to F25 contains starch and crospovidone studied range has no significant impact on the dissolution at $15 \mathrm{~min}$ and drug release observed more than $85 \%$. But, F19 and F20 contain $5 \mathrm{mg}$ of crospovidone with $5 \mathrm{mg}$ and $25 \mathrm{mg}$ of starch indicates there is a variation of dissolution rate $5 \mathrm{~min}$ and $10 \mathrm{~min}$. In addition, batches from F21 and F22 contain $25 \mathrm{mg}$ of crospovidone with $5 \mathrm{mg}$ and 25 mg of starch resulted to be higher dissolution rate comparatively with center point batches and reference drugs. Based on the evaluation of the design of experiments, surfactant (span $20 \mathrm{mg}$ ) with aerosil and without aerosil is very critical in the ritonavir formulation. Disintegrant such as crospovidone with binder such as starch 1500 and without starch 1500 is no critical in the atazanavir formulation. Hence, the optimum formulation was manufactured with two layers separately, such as S1layer (ritonavir) and S2layer (atazanavir sulfate) up to the final blend. Both blends are compressed by using bilayer Compression. Further, the impact of hardness was evaluated on the dissolution of both layers. As per fig. 16 , low hardness at $16 \mathrm{kP}$ has faster dissolution and high hardness at $28 \mathrm{kp}$ has slower dissolution. Overall, the studied hardness range has no significant impact on both layer. There is a variation of dissolution rate at initial time points and the studied hardness range comparable with the reference drug product. Bilayer compression followed by film coating was executed with opadry yellow of hydroxypropyl methylcellulose (HPMC) based coating with a solid concentration of $10 \% \mathrm{w} / \mathrm{w}$ and weight build-up was targeted for the $2.53 \%$ for each formulation. As per fig. 17, the finished product of fixed-dose formulation of dissolution results is comparable with each reference product of the innovator product. So, fixed dose of test formulation yielded the results of content uniformity, related substances, and physical appearance of finished product same as that of the reference product.

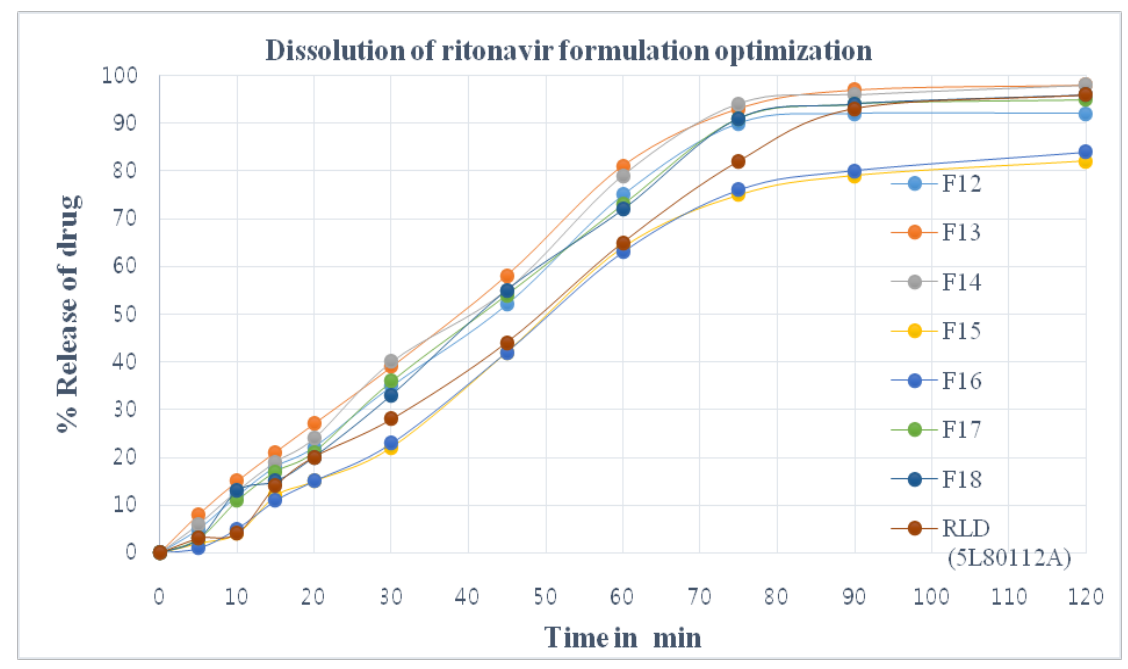

Fig. 14: Dissolution of ritonavir formulation optimization

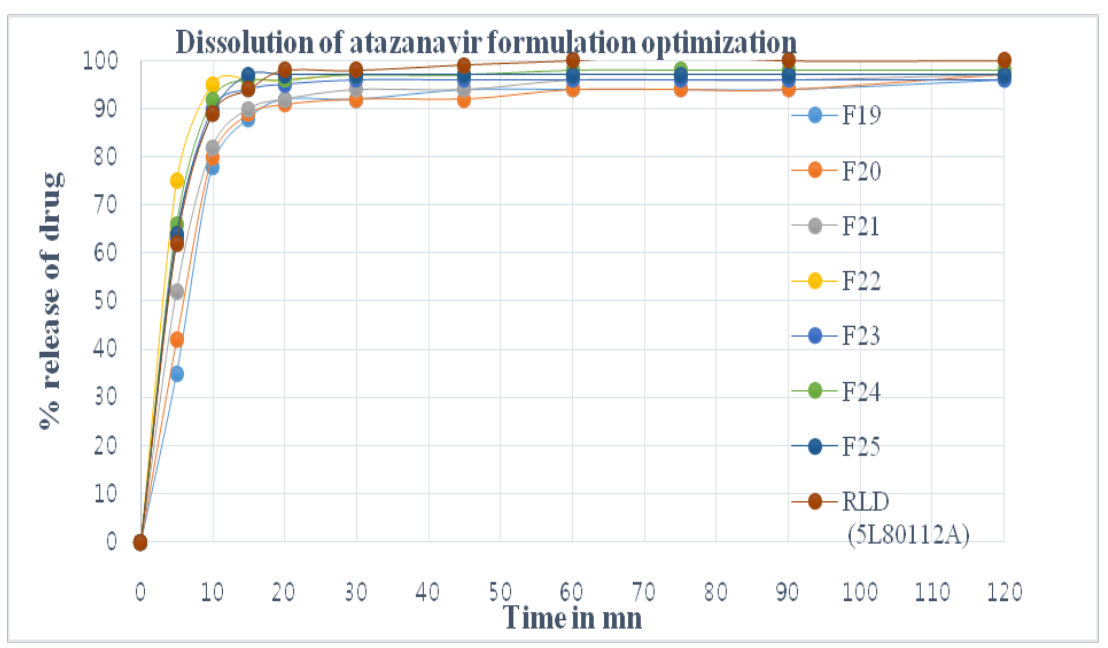

Fig. 15: Dissolution of atazanavir formulation optimization 


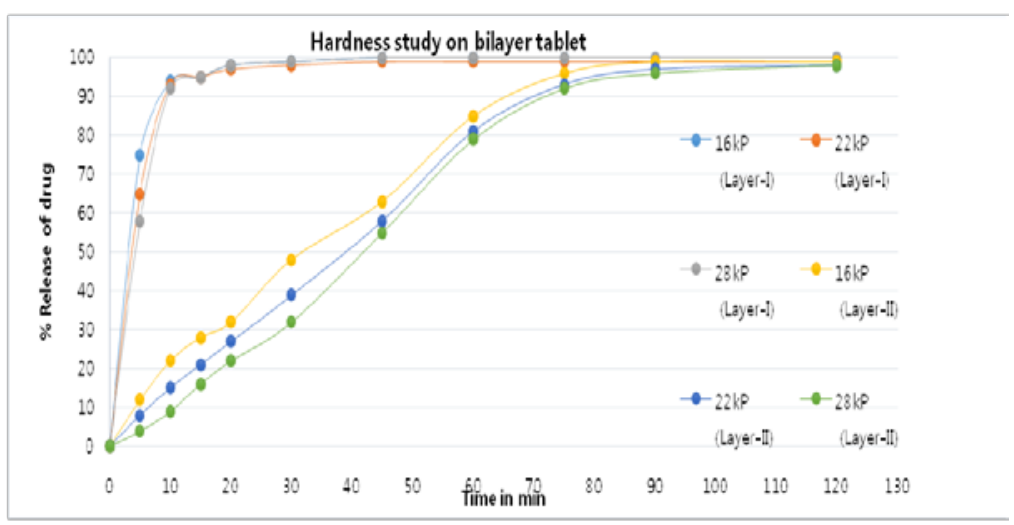

Fig. 16: Dissolution of hardness study on bilayer tablet

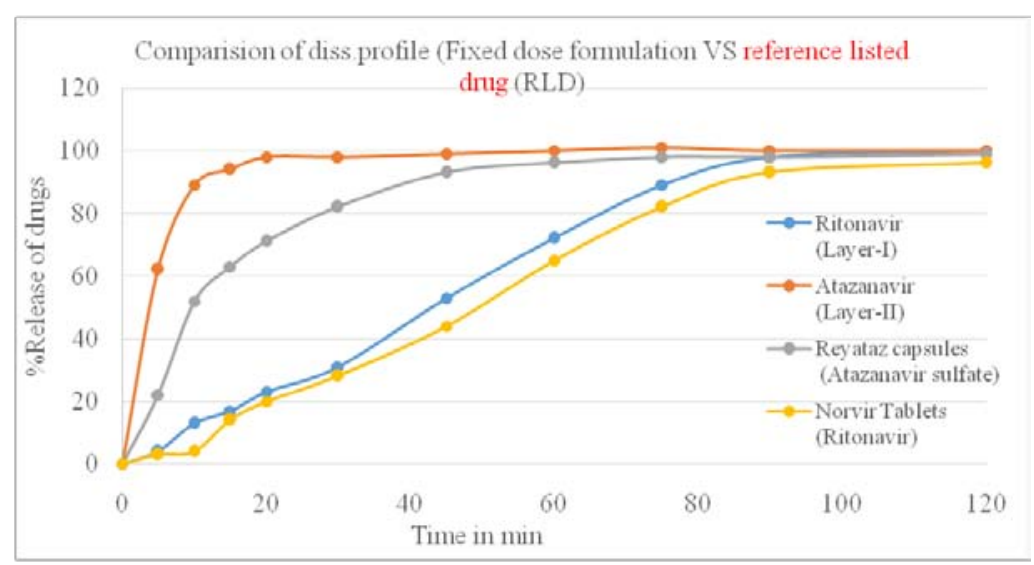

Fig. 17: Comparison of dissolution profile for fixed-dose formulation (test) vs reference product

\section{DISCUSSION}

Pre formulation study and drug-excipients compatibility study was carried out as per the international conference of harmonization (ICH) guidance. Bilayer formulation was designed for a fixed-dose combination of ritonavir and atazanavir sulfate as per the research and patents data [11-14]. Further, dissolution method development was established based on the solubility studies of both active substances $[17,18]$.

Initially, atazanavir formulation was designed by using direct compression [9] and resulted in poor flowability ad content uniformity issues was observed. Further, the wet granulation method was suggested to improve the flowability of the final blend [16]. Hence, diluent, binder, and disintegrant were selected based on the literature, and the studied range was fixed based on the handbook of excipients [20]. Finally, the formulation was optimized through the design of experiments (DOE) by using starch and crospovidone with different levels. Analysis of variance (ANOVA) for the model also shows significant. But, the studied range of starch and crospovidone from $10.00 \mathrm{mg}$ to $25.00 \mathrm{mg}$ has no significant impact on the dissolution because of the maximum drug was released within $85 \%$ at $15 \mathrm{~min}$ in the recommended dissolution media. Counter plot and overlay plot also suggest that the studied formulation of starch and crospovidone has no significant impact on the dissolution [21, 22]. Further, wet granulation improved the content uniformity and there is no interaction with the ritonavir layer.

In the case of ritonavir formulation, risk assessment was carried out for the formulation and process part as per the quality by design (QbD). Sodium lauryl sulfate $(40.00-80.00 \mathrm{mg})$ and colloidal silicon dioxide $(0.00-16.00 \mathrm{mg})$ range were selected to study the impact on the dissolution through the design of experiments [12-14]. Analysis of variance (ANOVA) for the model and factor-A in the formulation has a significant impact on the dissolution. Half-normal plot and counterplot indicates that sodium lauryl sulfate range has a significant impact on the dissolution and overlay plot revealed that lower range of sodium lauryl sulfate failure to meet the specification limit. Further, the hot-melt extrusion process of the ritonavir part, temperature, feed rate and screw speed was selected for the studyrelated substances. Analysis of variance (ANOVA) for the model, half normal plot for temperature shows significant on related substances and there is no impact on the dissolution. However, the 3D surface plot and counterplot indicates studied temperature range may impact on the related substances. But, the interaction of $A B$ and $A C$ factors shows significant as per the analysis of variance (ANOVA) and there is no evidence of impact on the dissolution of tablets. Finally, the overlay plot represents higher levels of temperature range impact on the related substances of finished product and failure to meet the specification $[21,22]$. So, the design of experiments through full factorial and fractional factorial design resulted to find the formulation and process range to control the dissolution and unknown impurities well within the limit. Further, all the excipients quantities were used for both layers of formulation followed to be within the inactive ingredients (IID) list as per the united stated food drug administration (USFDA) [23].

\section{CONCLUSION}

Fixed-dose formulation of ritonavir and atazanavir sulfate tablets $100 \mathrm{mg}$ was successfully manufactured with various percentages of diluents, solubilizers, polymers, and Disintegrants and finalized the stable formulation. Based on the solubility studies of active substances, a dissolution method was established. Compatibility studies were carried out for both mixtures of final blend formulations before the bilayer tablet compression for the safety of optimum formulation. Based on these studies confirmed that there is no interaction between both layers. Fractional factorial design and full factorial design were evaluated to understand the critical impact of formulation and process factors on the finished product. Design 
space was recommended for consistent results of the finished product. Further, the final product of fixed-dose formulation of ritonavir and atazanavir sulfate tablets $100 \mathrm{mg} / 300 \mathrm{mg}$ complies with the dissolution results with each formulation of atazanavir tablets $300 \mathrm{mg}$ and ritonavir capsules $100 \mathrm{mg}$. Overall the effect of fixed-dose formulation has synergetic than individual dosage forms of each tablet and capsule. It can be concluded that fixed-dose formulation available as a single dosage regimen and shows better in vitro drug release comparatively with innovator formulations and related substances observed to be well within the acceptable limit as per the international conference on harmonization (ICH) guidelines. Hence, the final formulation was stable and robust.

\section{ACKNOWLEDGEMENT}

The authors are very much thankful to the management of remedium laboratories and zeushygia life sciences, hyderabad for allowing utilizing the facilities for my research work.

\section{FUNDING}

Nil

\section{AUTHORS CONTRIBUTIONS}

All authors have contributed equally.

\section{CONFLICT OF INTERESTS}

The author declares that there are no conflicts of interest regarding the publication of the paper.

\section{REFERENCES}

1. Arun K Tiwari, Pawan K Porwal. Fixed-dose combination product: current status among regulatory. Res J Pharm Tech 2009;2:433-8.

2. Bangalore, S Shahane, A Parkar. Compliance and fixed-dose combination therapy. Curr Sci Inc 2007;9:184-9.

3. Jagannath Kota, Phaninatha Sarma Ayalavajjala. Development of orally administered fixed-dose combination (FDC) products: pharmacokinetic and biopharmaceutical considerations. Int J Sci Res 2015;3:161-73.

4. Shein Chung Chow. Bioavailability and bioequivalence in drug development. Wiley Int Rev Comput Stat 2014;6:304-12.

5. Dighe PP, T Hm. Design and statistical optimization of a bi layered tablet of metoprolol succinate sustained-release and atorvastatin calcium immediate release: once as day formulation in the management of hypertension. Asian J Pharm Clin Res 2018;11:293-302.
6. Pearl Pires Dighe, HM Tank. Formulation development and statistical optimization of as bilayer tablet of bosentan monohydrate and sildenafil citrate in management of pulmonary arterial hypertension. Int J Appl Pharm 2019;11:2.

7. Vishwakarma AG, Mogal RT, Pawar AY. Bi-layer tablet-a new ways in oral drug delivery system. Int J Pharm Tech Res 2014;6:1416-28.

8. International Conference of Harmonization (ICH). Harmonized tripartide guidelines for stability testing of new drug substances and products Q1A (R2). Rockville, MD: United States Pharmacopoeial Convention, Inc; 2003. p. 6.

9. Jampala Raj Kumar, P Narayana Raju, GV Radha, Aligeti Sravan Kumar. Design and evaluation of atazanavir sulfate noneffervescent sustained release floating matrix tablets. Global J Pharm Pharm Sci 2019;7:1-12.

10. K Kavya, P Sobhita Rani, A Pavani, E Rajareddy. Formulation and evaluation of immediate-release tablets of atazanavir. Int J Pharm Sci Rev Res 2014;24:119-23.

11. Patents. google.com/patent/US20120121722A1/en

12. Desai S, J Disouza, K Musle, $H$ Avinash. Solubility enhancement of ritonavir by hot-melt extrusion. Int J Pharm Sci 2016;8:309-12.

13. MA Repka, S Shah, J LU. Melt extrusion process to product. Expert Opinion Drug Delivery 2012;9:105-25.

14. Patents. google.com/patent/US20150045400A1/en

15. https://www.ema.europa.eu/en/documents/productinformation/ritonavir-mylan-epar-product-information_en.pdf. [Last accessed on 10 Mar 2021]

16. https://www.ema.europa.eu/en/documents/assessmentreport/atazanavir-mylan-epar-public-assessmentreport_en.pdf. [Last accessed on 10 Mar 2021]

17. https://extranet.who.int/pqweb/sites/default/files/HA632par t6.pdf. [Last accessed on 10 Mar 2021]

18. https://www.accessdata.fda.gov/scripts/cder/dissolution/dsp getalldata.cfm. [Last accessed on 10 Mar 2021]

19. Niraj S, Trasi, Sonal bhujbal, Qi Tony Zhou, Lynne S Taylor. Amorphous solid dispersion formation via solvent granulation-a case study with ritonavir and lopinavir. Int J Pharm 2019;X1:100035.

20. Handbook of pharmaceutical excipients. 9th edition. edited by Paul J Sheskey, Brune C Hancock, Gary P Moss, David J Goldfarb; 2020.

21. Hemant K Jain, Madhuri Taware. Formulation development and evaluation of gastro-retentive dosage form of atazanavir sulfate. Int J Pharm Sci 2018;10:60.

22. www.statease.com (DESIGN-EXPERT® VERSION 11 software) [Last accessed on 10 Mar 2021]

23. https://www.accessdata.fda.gov/scripts/cder/iig/index.cfm [Last accessed on 10 Mar 2021] 